\title{
The Effects of Trust on the Logistics Alliance's Stability
}

\author{
Yuqing Wei \\ School of Economics and Management \\ Beijing Jiaotong University \\ Beijing, China \\ weiyuqing2014@163.com
}

\begin{abstract}
Due to the distrust among logistics alliance members, the alliance's relationship becomes unstable, or even can be terminated. How trust affects the alliance's stability in the process of the cooperative game among logistics alliance members? Using a cooperative game model, this paper studies the effects of trust on the stability, through the discount and two kinds of threats. The results prove that mutual trust is the basis of a longterm cooperation and the mutual benefit between logistics service supplier and user.
\end{abstract}

Keywords- trust degree; logistics alliance; cooperative game

\section{INTRODUCTION}

The development of modern logistics requires the logistics integration, logistics alliance is important method to realize the integration, which is also important to reduce the logistics cost and strengthen the cooperation[1]. Between the trading of logistics alliance members, Jap s. d. (2003) points that if one member suspects the other has the "speculation", alliance cooperation will be unstable, even burst [2]; Enterprises Because of information asymmetry, one member "worries" about his action used by the other, and tends to choose noncooperation, which lead to the termination of cooperation.

Trust is a key to influence the stability of the alliance, when trust degree low to a certain limit, the alliance stability level will change and the alliance will be dissolved. Wang Jianxi(2010) and Ding Jian (2011) point that logistics alliance members low goes against the stability maintenance[3],[4]. Ji Yiming (2009) and Lin Qiang (2012) research on quantitative analysis on trust degree by determining the trust value of the logistics alliance[5],[6]. Chen Juhong (2011)research on the quantitative trust from the perspective of income, explaining the relationship between benefit and cost of distrust and he relationship between the enterprise benefit and the trust benefit[7].

Trust is the foundation of logistics alliance cooperation, trust degree affects the alliance cooperation and stability. The paper shows that the effects from the trust degree on the alliance stability, and explains that the trust degree has an important function to maintain the alliance stability.

\section{THE MODEL ASSUMPTION}

The alliance participants in the logistics alliance cooperative game model discussed in this paper are logistics service demanders (such as manufacturing enterprises, circulation enterprises, etc.) and logistics service suppliers (such as the third party logistics enterprise, the enterprise internal logistics organizations, etc.), the cooperation between alliance members is based on logistics activities. The game model of logistics alliance has four characteristics. (1)Strategies experience interaction, forming a binding agreement, such as a contract; (2) at the beginning of the cooperation, the members don't know the strategy each other, but in the process of cooperation for a long time, the members make strategy in order, and the latter can observe the former; (3) the member can fully understand strategy characteristics and strategic paths each other; (4) because the members can't predict the end of the logistics service at the beginning of the cooperation, they need to make several choices in different stages. To sum up, the cooperation process of the logistics alliance showed in this paper involves cooperative game, complete information game, static game, dynamic game and repeated game.

In the logistics alliance cooperative game, suppliers and demanders both have two strategies: cooperation and noncooperation. Both sides have different benefits for different strategies, and the pay-off matrix between the members is shown in the table 1. C is on behalf of "cooperation", $\mathrm{N}$ on behalf of "noncooperation". In each strategy combination, both game sides benefit expression in each group is on behalf of the demander income and the supplier income, for example, $\mathrm{P}_{\mathrm{D}} \mathrm{NC}$ stands for the demander benefit when the demander chooses "noncooperation" and the supplier chooses "cooperation", and so on. The demander benefit are $\mathrm{P}_{\mathrm{D}} \mathrm{CC}, \mathrm{P}_{\mathrm{D}} \mathrm{C}, \mathrm{P}_{\mathrm{D}} \mathrm{NC}$ and $\mathrm{P}_{\mathrm{D}} \mathrm{NN}$, $\mathrm{PDNC}$ and PDNN and the supplier benefit are $\mathrm{P}_{\mathrm{S}} \mathrm{CC}, \mathrm{P}_{\mathrm{S}} \mathrm{CN}$, $\mathrm{P}_{\mathrm{S}} \mathrm{NC}$ and $\mathrm{P}_{\mathrm{S}} \mathrm{NN}$ in different strategies.

TABLE I. THE PAY- OFF MATRIX IN THE GAME

\begin{tabular}{|c|c|c|}
\hline & \multicolumn{2}{|c|}{ Supplier } \\
\hline Demander & cooperation & noncooperation \\
\hline noncooperation & $\mathrm{P}_{\mathrm{D}} \mathrm{NC}, \mathrm{P}_{\mathrm{S}} \mathrm{NC}$ & $\mathrm{P}_{\mathrm{D}} \mathrm{NN}, \mathrm{P}_{\mathrm{S}} \mathrm{NN}$ \\
\hline cooperation & $\mathrm{P}_{\mathrm{D}} \mathrm{CC}, \mathrm{P}_{\mathrm{S}} \mathrm{CC}$ & $\mathrm{P}_{\mathrm{D}} \mathrm{CN}, \mathrm{P}_{\mathrm{S}} \mathrm{CN}$ \\
\hline
\end{tabular}

The model needs to satisfy the following conditions:

Condition 1: For the demander, the different benefits satisfy the inequality: ${ }_{D}{ }_{D} C>P_{D} C C>P_{D} N N>P_{D} C N$. Similarly, for the 
supplier, the different benefits satisfy the inequality: $\mathrm{P}_{\mathrm{S}} \mathrm{CN}>\mathrm{P}_{\mathrm{S}} \mathrm{CC}>\mathrm{P}_{\mathrm{S}} \mathrm{NN}>\mathrm{P}_{\mathrm{S}} \mathrm{NC}$.

The inequalities show that the party for irregularities can gain more benefit at the expense of the alliance benefit when the strategies of the two sides is different, namely one strategy is "cooperation" and the other is "noncooperation". That is the meaning for $\mathrm{P}_{\mathrm{D}} \mathrm{NC}>\mathrm{P}_{\mathrm{D}} \mathrm{CC}, \mathrm{P}_{\mathrm{S}} \mathrm{CN}>\mathrm{P}_{\mathrm{S}} \mathrm{CC}$. However, the side choosing cooperation needs to bear the loss caused by opportunistic behavior, the benefit is less than that for the noncooperation strategy. That is the meaning for $\mathrm{P}_{\mathrm{D}^{N N}}>\mathrm{P}_{\mathrm{D}} \mathrm{CN}, \mathrm{P}_{\mathrm{S}} \mathrm{NN}>\mathrm{P}_{\mathrm{S}} \mathrm{NC}$. In this way, the logistics alliance overall benefit is decreased.

when the strategies of the two sides is consistent, namely either side chooses "cooperation" or "cooperation" strategy, the benefit $\left(\mathrm{P}_{\mathrm{D}} \mathrm{CC}, \mathrm{P}_{\mathrm{S}} \mathrm{CC}\right)$ of the strategy combination (cooperation, cooperation) is more than the benefit $\left(\mathrm{P}_{\mathrm{D}} \mathrm{NN} \mathrm{P}_{\mathrm{S}} \mathrm{NN}\right)$ of the strategy combination (noncooperation, noncooperation), and both sides have to bear a certain loss when the they choose "no cooperation". However, (noncooperation, noncooperation) is the only pure strategy Nash equilibrium in the matrix, (cooperation, cooperation) is not the Nash equilibrium in the game. logistics alliance cooperative game has "prisoners dilemma". In this game, ( $\left.\mathrm{P}_{\mathrm{D}} \mathrm{NC}-\mathrm{P}_{\mathrm{D}} \mathrm{CC}\right)$ stands for "speculation" motives, namely the additional revenues $\Delta P_{D}$ due to the demander noncooperation caused by the speculative behavior. ( $\mathrm{P}_{\mathrm{D}} \mathrm{NN}-\mathrm{P}_{\mathrm{D}} \mathrm{CN}$ ) stands for "worry", namely the demander cooperation has to bear the alliance loss $\Delta L_{D}$ caused by supplier noncooperation.

Condition 2: The probability that one side predict the other side to make "cooperation" strategy is p, (1-p) stands for one side to the other's trust degree .

The definition of trust in a logistics alliance draw lessons from the definition of trust in the research of Peter and says Willem (1997). That is defined the alliance trust is the probability of that one side predict the other side to make "cooperation" strategy between the cooperative enterprise[8]. Similarly, trust in the logistics alliance can be defined as: the probability of that one side predict the other side to make "cooperation" strategy between the supplier and demander, namely the probability of that one side has to bear the alliance loss caused by the other side's "noncooperation" strategy.

Condition 3: Logistics alliance cooperative game is infinitely repeated game, one member makes trigger strategy according to the other's strategy. In the first stage, the strategies of demander and supplier are both "cooperation", demander benefit is $\mathrm{P}_{\mathrm{D}} \mathrm{CC}$, and demander strategy in the next stage will be "cooperation"; If supplier strategy is "noncooperation", the demander has to bear the alliance loss $\mathrm{P}_{\mathrm{D}} \mathrm{CN}$, and demander strategy in the next stage will be "noncooperation" to take revenge on the supplier. That is the side have to take supplier's revenge for his speculation. The speculator have to look for another partner, bearing cooperation cost. If the members' strategy profile is (cooperation, cooperation), the members' strategy profile from the second stage to the end stage and strategy profile in the first stage are the same, that is the two sides will always choose cooperative strategies. The equilibrium is (cooperation, cooperation) in logistics alliance cooperative game.

Condition 4: The condition of stable cooperation in logistics alliance is the cooperative benefit higher than the uncooperative benefit. The discount coefficient a stands for the importance of the cooperative benefit for members. $R_{D}$ stands for the present value of total net income when demander strategy is "cooperation" in every stage of repeated game, the demander's total net income is $a R_{D}-C$. By the same token, the supplier's total net income is $a R_{S^{-}} C$.

Condition 5: $\Delta P_{D}=\mathrm{P}_{\mathrm{D}} \mathrm{NC}-\mathrm{P}_{\mathrm{D}} \mathrm{CC}$ is demander's additional revenue for unilateral uncooperative strategy according to Condition 1, $\Delta L_{D}=\mathrm{P}_{\mathrm{D}} \mathrm{NN}-\mathrm{P}_{\mathrm{D}} \mathrm{CN}$ is the supplier's loss for unilateral cooperative strategy. Similarly, the supplier's additional revenue and loss respectively are $\Delta P_{S}=\mathrm{P}_{\mathrm{S}} \mathrm{CN}-\mathrm{P}_{\mathrm{S}} \mathrm{CC}$, $\Delta L_{S}=\mathrm{P}_{\mathrm{S}} \mathrm{NN}-\mathrm{P}_{\mathrm{S}} \mathrm{NC}$. The game need to satisfy the inequalities $\Delta P_{D}>\Delta L_{D}, \Delta P_{S}>\Delta L_{S}, \max \left\{\Delta P_{D}, \Delta P_{S}\right\}<\left(\Delta L_{D}+\Delta L_{S}\right)$, that is either uncooperative strategy will lead to loss and the additional revenue for unilateral speculation is at the expense of the alliance benefit.

\section{THE LOGISTICS ALLIANCE COOPERATIVE GAME MODEL}

\section{A. The Prerequisites to Ensure the Demander be Unwilling to Deviate from the Cooperative Path}

To ensure the demander be unwilling to deviate from the cooperative path is in a priority position. The cooperation cost $\mathrm{C}$ is less than total net income lost for uncooperative strategy, namely to satisfy the inequality(4.1) .

$$
\begin{aligned}
& C<a R_{D}-C, \\
& \text { t.e. }^{\mathrm{a}>2 C / R_{\mathrm{D}}}
\end{aligned}
$$

B. The Condition for Cooperative Game Equilibrium as the Demander is Unwilling to Deviate from the Cooperative Path

The demander and the supplier will make trigger strategy in logistics alliance infinitely repeated game On the when the demander is unwilling to deviate from the cooperative path. If both sides choose cooperative strategies at the beginning, the members will always choose "cooperation" in the later stages, namely to get the equilibrium (cooperation, cooperation), the cooperative relationship is stable. Combined with Condition 2, Condition 3, Condition 4 and Condition 5, the net income for demander's uncooperative strategy and cooperative strategy respectively are $p\left(\Delta P_{D}-C\right),(1-p)\left(a R_{D}-C\right)-p \Delta L_{D} \quad$.The equilibrium satisfies the inequality (4.2).

$$
p \Delta P_{D}<(1-p)\left(a R_{D}-C\right)-p \Delta L_{D}
$$




$$
\text { l.e. } a>\left[p /(1-p)\left(\Delta P_{D}+\Delta L_{D}\right)+C\right] / R_{D}
$$

Combined with inequalities (4.1) (4.2), when $0<C<p\left(\Delta P_{D}+\Delta L_{D}\right)$ and $a>\left[p /(1-p)\left(\Delta P_{D}+\Delta L_{D}\right)+C\right] / R_{D}$, cooperative game for the perspective of the demander gets the equilibrium and the cooperative relationship is stable.

\section{The Condition for Cooperative Game Equilibrium as the Supplier is Unwilling to Deviate from the Cooperative Path}

Based on inequalities (4.1)(4.2), when $0<C<p\left(\Delta P_{S}+\Delta L_{S}\right)$ and $a>\left[p /(1-p)\left(\Delta P_{S}+\Delta L_{S}\right)+C\right] / R_{S}$, cooperative game for the perspective of the supplier gets the equilibrium and the cooperative relationship is stable.

In conclusion, when the formula M: $0<C<p \times \min \left\{\Delta P_{D}+\Delta L_{D}, \Delta P_{S}+\Delta L_{S}\right\}$, the discount coefficient $a$ needs to satisfy inequality (4.3).

$$
a>\max \left\{\begin{array}{l}
{\left[p /(1-p)\left(\Delta P_{D}+\Delta L_{D}\right)+C\right] / R_{D},} \\
{\left[p /(1-p)\left(\Delta P_{S}+\Delta L_{S}\right)+C\right] / R_{S}}
\end{array}\right\}
$$

\section{CONCLUTIONS}

Due to the equal position for the demander and the supplier in the logistics alliance cooperative game, the strategies of them are consistent, this paper analyses influences of variable $p$ on discount coefficient $a$ and game results in the demander situation, and the influences are the same as the supplier situation, specific conclusions are described as follow.

Conclusion 1: As the discount coefficient $a$, the higher, the more attention on the future benefit for the demander. The lower, the more attention on the immediate benefit for the demander. Obviously, when the trust degree reaches to a certain boundary, obtaining a appropriate discount value, the strategy profile is (cooperation, cooperation). In a given value of $a$, the higher the value of formula $\mathrm{M}$, the more attractive the uncooperative strategy is, and vice versa.

Conclusion 2: The member strategy choices depend on equilibrium results of logistics alliance cooperative game.

The formula: $a>\left[p /(1-p)\left(\Delta P_{S}+\Delta L_{S}\right)+C\right] / R_{S}$ stands for the believable threat to prevent members selecting uncooperative strategy, and the logistics alliance cooperative game trends to a stable equilibrium (cooperation, cooperation), and vice versa. However, this is not the result that a logistics alliance want to achieve.

Conclusion 3: Trust degree is the certainly need insufficiency condition for the establishment and development of cooperative relationship.
When $p=1$, there is no trust between the supplier and the demander with the formula $\mathrm{M}$ value tending to infinity. There is no cooperation between the members, that is, the cooperation is based on a certain trust degree. When $p=0$, the formula $\mathrm{M}$ : $a>\max \left\{C / R_{D}, C / R_{S}\right\}$ can't be sure to be satisfied. So trust is not a sufficient condition of the alliance cooperation.

Conclusion 4: Trust degree make influences on two kinds of threats ("speculation" and "worry") to choose strategies.

The main threats for the cooperative relationship are "speculation" and "worry", that is the additional revenues due to the demander noncooperation caused by the speculative behavior, and the cooperation strategy of one side bearing the alliance loss caused by noncooperation of the other side. In inequality (4.3), the coefficient $p /(1-p)$ of "speculation" and "worry" is an increasing function about trust degree. The coefficient $p /(1-p)$ is reducing with the increase of trust degree, namely the decrease of $p$, the increase of (1-p), and the decrease of the value of $\mathrm{M}$, which leads cooperative strategy be more attractive for the members better for the establishment the stable development of a logistics alliance.

In conclusion, trust degree is the certainly need insufficiency condition for the establishment and development of cooperative relationship. The members will make a uncooperative strategy caused by the threats of "speculation" and "worry" to look forward to more benefit or less loss. The increase of trust degree can reduce the risk caused by "speculation" and "worry" for a logistics alliance. The higher the value of cooperative benefit $R$, The greater the chance to choose the cooperative strategy. To sum up, a reasonable discount based on the trust degree is conducive to improve the stability of the alliance cooperation, and mutual trust is basis of mutual benefit and a long-time cooperation.

\section{REFERENCES}

[1] Lihua Li, Zhengdong $\mathrm{Hu}$, Evaluation game model about symbiosis of asymmetric logistics alliance [J].Changsha University of Technology: Natural Science Edition, 2012, 9 (1): 29-33.

[2] Jap S.D., Anderson E. Safeguarding interorganizational performance and continuity under ex post opportunism [J].Management Science, 2003,49(12): 1684-1701.

[3] Jianxi Wang, The research on the model of synergetic development of logistics industry and manufacturing industry in China [D]. Wuhan: Wuhan Technological University, 2010.

[4] Jian Ding. Fedeate opportunistic behavior and prevention for third-party logistics stategic [D]. Qingdao Technological University, 2011.

[5] Yiming Ji. The Trust-drive in Supply Chain Cooperation [J].Lanzhou University: Social Science Edition, 2009, 37 (4): 94-97.

[6] Qiang Lin, NAREN Gao-wa, Wenting Xu, Trust mechanism based on process in supply chain enterprise cooperation [J]. Journal of tianjin university (social science edition), 2012, 14(3):193-196.

[7] Juhong Chen, Jun Zhang, Fuli Guo, contract design between manufacturing enterprises and TPL enterprises subject to trust constrains [J]. East China economic management, 2011,25(5):119-121.

[8] Hwang P, Burgers W P. Properties of trust: An analytical view[J]. Organizational behavior and human decision processes, 1997, 69(1): 6773. 